\title{
Therapeutic Approaches to Streptococcal Toxic Shock Syndrome
}

\author{
Gio J. Baracco, MD, and Alan L. Bisno, MD
}

\begin{abstract}
Address
D epartment of Medicine, D ivision of Infectious D iseases, U niver sity of Miami School of Medicine; Medical Service, Miami Veterans Affairs Medical Center (111), 1201 N W 16th Street, Miami, FL 33125, USA.

Current Infectious Disease Reports 1999, 1:230-237

Current Science Inc. ISSN 1523-3847

Copyright @ 1999 by Current Science Inc.
\end{abstract}

The streptococcal toxic shock syndrome (ST SS) is a severe, life-threatening condition characterized by hypotension and multiorgan system dysfunction associated with infection by the group A Streptococcus (GAS) or rar ely by streptococci of other Lancefield serogroups. It is associated with a soft tissue infection, such as necrotizing fasciitis, in abo ut half of the cases; the remainder are secondary to a variety of other invasive and no ninvasive GAS infections. Although the pathophysiology of STSS is not yet fully understood, there are compelling reasons to believe that the syndrome results at least in part from the action of the streptococcal pyrogenic exotoxins, which act as superantigens. Patients with STSS should be admitted to an intensive care unit for support of cardiovascular, respiratory, and renal function as required. In experimental models of overwhelming GAS infection, clindamycin has greater efficacy than penicillin, and therapy with this agent is recommended. Penicillin, to which GAS are unifo rmly susceptible, may be used in addition to clindamycin. Limited clinical experience, most of which is anecdotal, suggests marked improvement in some STSS patients after administration of intravenous immunoglobulin. Even in the absence of conclusive data, the potential benefits of intravenous immunoglobulin in this highly lethal disease make its use reasonable in life-threatening cases. 0 ther experimental approaches are also discussed, such as the use of anti-tumor necrosis factor monoclonal antibodies and plasmapheresis.

\section{Introduction}

The streptococcal toxic shock syndrome (STSS) is a severe, life-threatening condition characterized by hypotensio and multiorgan system dysfunction associated with infection by the group A Streptococcus (GAS). STSS is associated with a soft tissue infection such as necrotizing fasciitis, myonecrosis, or cellulitis in about $50 \%$ of cases [1,2]. It has, however, followed a variety of other streptococcal infections such as pneumonia, meningitis, sinusitis, endophthalmitis, pancreatitis, peritonitis, puerperal sepsis, septic arthritis, pharyngitis, and retroperitoneal necrotizing fasciitis [2-7]. In as many as $20 \%$ of patients, no site of infection is apparent at the time of presentation $[3,8 \cdot]$. Approximately $60 \%$ of patients are bacteremic, and in one half of bacteremic patients the source of infection cannot be ascertained [1,2].

The microorganism most frequently isolated and the one classically associated with this condition is the GAS. Most studies have shown that strains of the M-protein serotypes 1 and 3 are those most frequently isolated from patients with STSS [1,8•]. Moreover, among patients experiencing invasive GAS disease, infection with an organism of the $\mathrm{M}-1$ serotype has been associated with an increased risk of developing STSS [8•]. In a recent series, however, these serotypes accounted for only $37.5 \%$ of the isolates, with the remaining isolates belonging to multiple other serotypes or being non-M-typable [9]. STSS has al so been described after infections with streptococci from the Lancefield groups B, C, and G [10-15] and Streptococcus suis [16].

\section{Epidemiology}

Extremes of age, HIV infection, cancer, heart disease, diabetes mellitus, lung disease, al cohol abuse, and active varicella infection have been identified as risk factors for invasive GAS disease [17]. Are there specific risk factors for the development of STSS among persons with invasive GAS disease? Population-based studies are at variance on this point. Zurawski et al. [9] found no clear differences in age distribution or underlying disease state between patients with or without STSS in metropolitan Atlanta. Eriksson et al. [8•] studied invasive GAS disease in Stockholm; multivariate logistic regression analysis reveal ed alcohol abuse and infection with type $M-1$ organisms to be significantly associated with STSS. In Ontario, Davies et al. [17] found STSS patients to be older, morelikely to have an underlying chronic illness, and less likely to have nosocomial disease than others with invasive disease

Most STSS patients have an obvious percutaneous portal of entry, including surgical and nonsurgical acute wounds, chronic skin ulcers, illicit injection of intravenous drugs [3,9], superinfection of varicel la lesions [9,18-20], or rarely even acupuncture [21]. It is believed that most of the other patients acquire the infection via the pharyngeal or the vaginal mucosa [1]. 
It has been postulated that the use of nonsteroidal anti-inflammatory agents (NSAIDs) might facilitate the progression of streptococcal infections to STSS, since these agents adversely affect granulocyte chemotaxis, phagocytosis, and bacterial killing and enhance the production of tumor necrosis factor (TNF) [22]. However, no such association has been demonstrated in clinical studies $[9,23]$. Moreover, the issue has been difficult to assess because of the ready avai lability of NSAIDs and the frequency with which they are employed in patients experiencing fever and pain, two early symptoms of invasive GAS di sease and STSS.

\section{Pathogenesis and Pathophysiology}

Although the pathogenesis and pathophysiology of STSS are not yet fully understood, there are compelling reasons to believe that the syndrome results in large part from the action of streptococcal toxins, most of which are extracel lularly elaborated. Indeed, the very name of this entity proclaims its similarity to the toxic shock syndrome caused by Staphylococcus aureus, a disorder known to betoxin mediated. Moreover, certain GAS toxins bear considerable structural and functional similarity to those produced by $S$. aureus.

Of particular interest in regard to STSS are the streptococcal pyrogenic exotoxins (SPE), of which five are currently known. These include SPE-A, SPE-B, SPE-C, mitogenic factor (MF, SPE-F) and streptococcal superantigen (SSA). Most of the SPE function as superantigens $[5,26,27]$, and $M$ protein has al so been reported to possess superantigenic activity.

Superantigens are a group of very powerful immunostimulatory molecules produced by bacteria and viruse $[25,26]$. They induce massive T-cell proliferation by their ability to bind directly to both the major histocompatibility complex (MHC) class II molecule outside the antigenbinding cleft on the antigen-presenting cell and to a spe cific $V \beta$ region of the $T$-cell receptor, thus circumventing normal antigen recognition and processing. A superantigen may activate as many as $3 \%$ to $10 \%$ of the entire T-cell population, often all those expressing the specific $V \beta$ chain to which the superantigen binds [27]. In contrast, conventional antigens, which have to match all five elements of the T-cell receptor $\left(V_{\alpha}, J \alpha, V \beta, D \beta, J \beta\right)$, activate approximately $0.01 \%$ to $0.1 \%$ of the body's T cells (Fig. 1) [28].

Such nonspecific stimulation of T lymphocytes results in an unbridled release of cytokines, including TNF- $\alpha$, TNF- $\beta$, interleukin (IL)-1, and IL-6 [29], which may well underlie the hypotension and multiorgan dysfunction seen in STSS. The initial proliferation of T cells in response to superantigens is followed by the rapid depletion of T-cell subsets bearing the specific $\beta$ subunit through accel erated programmed cell death (apoptosis) [25].

The conventional pathways of antigen presentation and processing also play a role in the devel opment of STSS [30 •]. Cytokine production has been induced by pepti-

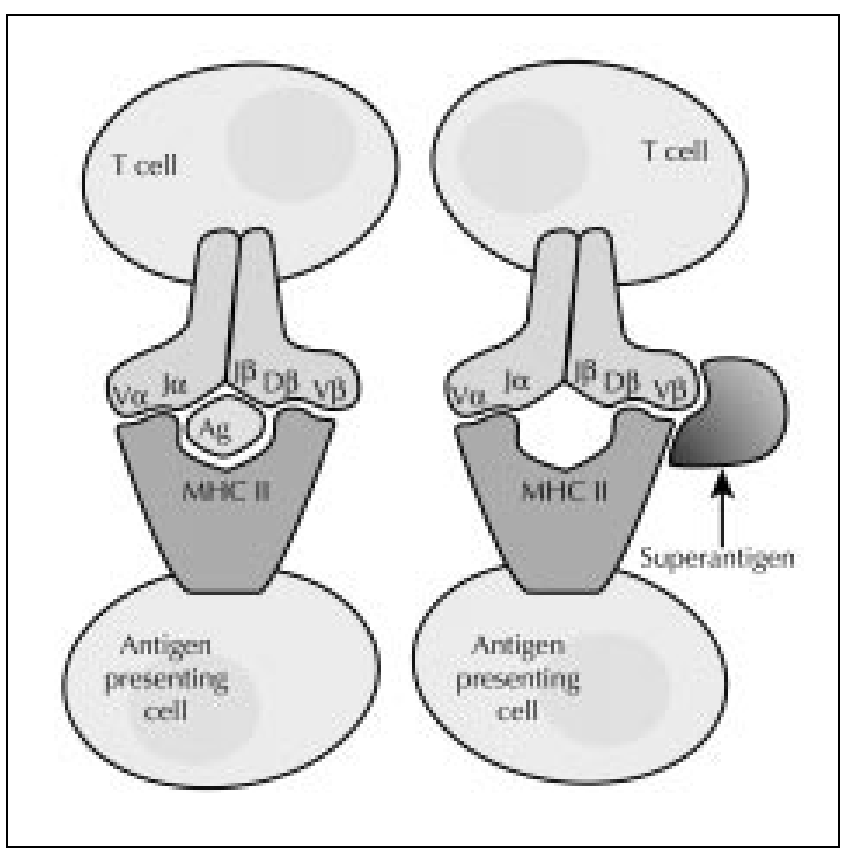

Figre 1. Interaction of antigens and superantigens with the antigen presenting cell and the Tlymphocyte. $\mathrm{Ag}$ - antigen; $\mathrm{MHC}$ - major histocompatibility complex. Adapted from Manders [28]; with permission.

doglycan, lipoteichoic acid, exotoxins such as streptolysin $O$, and killed streptococci [31] by these more common mechanisms. SPE-B is a cysteine protease that has bee shown in mice to be critical for the pathogenicity of invasive GAS disease [32] and to increase the production of IL$1 \beta$ by cleaving its percursor [33].

The conclusion that TNF plays a central role is supported by the observation that high levels of TNF wer observed in a baboon model of group A streptococcal bacteremia at a point in time when profound hypotension was manifest. In addition, a neutralizing monoclonal antibody against TNF restored normal blood pressure and reduced mortality by $50 \%$ in the same model [34].

Noncytokine mechanisms of shock may also pla role. Recently, a cysteine protease produced by group A streptococci was shown to rel ease bradykinin, which is a very potent vasodilator and could be at least partially responsible for the early hypotension seen in STSS [35].

Why certain peopleinfected with virulent toxigenic GAS strai ns develop STSS, invasive infection without STSS, or carry the same organism asymptomatically (as shown byDNAmacrorestriction analysis [36] and by pul sed-field gel electrophoresis [37-]) is not known. It has been postulated that in order to devel op STSS, the patient must lack both specific antibodies neutralizingSPE and opsonizing M protein [38-40]

\section{Diagnosis}

Streptococcal toxic shock syndromemanifests initial ly with myal gia, malaise, chills, fever, nausea, vomiting, and diarrhea, followed later by tachycardia, tachypnea, and evidence of 


\section{Table 1 Case definition for the streptococcal toxic shock syndrome}

\section{Clinical case definition}

An illness with the following clinical manifestations occur ring within the first 48 hours of hospitalization or, for a nosocomial case, within the first 48 hours of illness:

$\mathrm{H}$ ypotension defined by a systo lic blood pressure $\leq 90 \mathrm{~mm} \mathrm{H}$ g for adults or less than the fifth percentile by age for children aged less than 16 years.

Multiorgan involvement characterized by two or more of the following:

1. Renal impairment: C reatinine $\geq 2 \mathrm{mg} / \mathrm{dL}(\geq 177 \mu / \mathrm{L})$ for adults or $\geq$ twice the upper limit of normal for age. In patients with preexisting renal disease, a greater than two fold elevation over the baseline level.

2. Coagulopathy: Platelets $\leq 100,000 / \mathrm{mm}^{3}\left(\leq 100 \times 10^{6} / \mathrm{L}\right)$ or disseminated intravascular coagulation, defined by prolonged clotting times, low fibrinogen level, and the presence of fibrin degradation products.

3. Liver involvement: A lanine aminotransferase, aspartate aminotransferase, or total bilirubin levels $\geq$ twice the upper limit of normal for the patient's age. In patients with preexisting liver disease, a greater than twofold increase over the baseline leve.

4. A cute respiratory distress syndrome: defined by acute onset of diffuse pulmonary infiltrates and hypoxemia in the absence of cardiac failure or by evidence of diffuse capillary leak manifested by acute onset of gener alized edema, or pleural or peritoneal effusions with hypoalbuminemia.

5. A generalized erythematous macular rash that may desquamate.

6. Soft tissue necrosis, including necrotizing fasciitis or myositis, or gangrene.

\section{Laboratory criteria for diagnosis}

Isolation of group A Streptococcus.

\section{Case classification}

Probable: A case that meets the clinical case definition in the absence of another identified etiology for the illness and with isolation of group A Streptococcus from a nonsterile site.

Confirmed: A case that meets the clinical case definition and with isolation of group AStreptococcus from a nor mally ster ile site (eg, blood or cerebrospinal fluid or, less commonly, joint, pleural, or pericardial fluid).

Adapted from Centers for Disease Control and Prevention [42].

shock and organ failure [1]. Included in the clinical picture are also symptoms associated with the primary infection. In the case of necrotizing fasciitis, for example, severeand unrelenting deep pain out of proportion to thecutaneousfindings is frequently seen. The diagnosis of STSS is made on dinical and laboratory data according to thecase definition proposed by the Working Group on Severe Streptococcal Infections[41] and revised by the Centers for Disease Control and Preven tion in September, 1996 (Table1) [42]

\section{Therapy}

Proper antibiotic therapy and aggressive supportive care are essential components in the treatment of invasive GAS disease and toxic shock. If necrotizing fasciitis is present, prompt surgical intervention with radical debridement of all infected tissues is virtually al ways required and may be life saving [43]. Several other interventions directed towards arresting the immunologic and inflammatory mechanisms responsible for STSS have been proposed to be beneficial in the management of this condition.

\section{Supportive therapy}

Patients with STSS should be admitted to an intensivecare unit. Resuscitation often requires copious volumes of intravenous fluids. Inotropic agents, blood products, mechanical ventilation, and hemodialysis should be used as indicated by the patient's condition. Invasive hemodynamic monitoring is usually required.

\section{Antimicrobials}

Penicillin

Streptococci of Lancefield groups A, B, C, and G are universally susceptible to penicillin $[44,45]$, which remains the drug of choice in the early treatment of invasive as well as noninvasive Streptococcus pyogene infections [46]. There is, however, an important caveat. Penicillin exerts its bactericidal activity by binding to certain enzymes (penicillinbinding proteins) involved in bacterial cell wall synthesis. The antimicrobial effect is thus expressed primarily in rapidly replicating bacteria and is greatly attenuated in cultures that have reached the stationary phase of growth. Organisms in such cultures decrease their expression o certain penicillin-binding proteins and become less susceptible to penicillin. This phenomenon (inoculum effect or Eagle effect) [47] has been demonstrated both in vitro and in the GAS myositis mouse model.

Inoculum sizeisamajor factor in determining the efficacy of penicillin in the experimental treatment of deep-seated streptococcal infections [47]. With large inocula, the stationary phase of streptococcal growth in vivo may be reached sooner than with smaller inocula. Therefore, alarge inocul um or a delayed treatment increases the probability of failure of penidillin. This isdue to aslower growth rateof bacteriain the 
infected tissues (analogous to the stationary growth phase of cultures in vitro) and not merely to the bacterial concentration per se $[47,48]$. In this setting, antimicrobials activeat the ribosomal level weremore effective than penicillin in decreasing lethality in the mousemyositis model $[47,48]$

\section{Clindamycin}

The efficacy of clindamycin is likely related to its ability to suppress thesynthesis of proteins, including M protein and bacterial exotoxins, and to the fact that its mode of action is independent of the phase of bacterial growth [48]. It may also enhance certain host responses to infection such as phagocytosis and intracellular killing [47]. It has been shown that clindamycin has greater efficacy than penicillin in treating experimental myositis caused by two toxin-producing, gram-positive bacterial species, S. pyogenes (Fig. 2) and Clostridium perfringens [48]. This theoretical advantage, however, has not been validated in any controlled study, and clindamycin is often used in addition to (as opposed to instead of) penicillin or another cell wall-active agent [49]. In in vitro timed-kill studies using clinically relevant antimicrobial concentrations such combinations are neither antagonistic nor synergistic [50•].

\section{M acrolides}

Erythromycin is generally recommended as the therapy of choice for common streptococcal throat and skin infections in penicillin-allergic individuals [51]. It has also been found to be more effectivethan penicillin, al though less so than clindamycin, in the GAS myositis mouse model [48]. Moreover, approximately $5 \%$ of GAS isolates in the United States are resistant to erythromycin and to other macrolides [45]. This figure is considerably higher in some other countries. At the present time there is no indication for the use of erythromycin or other macrolide congeners in the treatment of STSS.

\section{Vancomycin}

Holdsworth et al. [52] reported two patients with lifethreatening GAS soft tissue infection who failed to respond to intravenous penicillin (even though the microorganisms were fully sensitive in vitro) but who improved dramatically when treated with vancomycin. Only one of the cases was proven bacteriologically to be due to GAS; the diagnosis in the second case was based on the clinical picture and a diagnostic rise in the serum titer of antistreptolysin $O$.

Vancomycin is an attractive alternative to penicillin because GAS are uniformly susceptible to it, it is bactericidal at therapeutic concentrations, and it has a long halflife and a long postantibiotic effect. Although, like penicillin, vancomycin interferes with cell wall synthesis, it does so by complexing with D-alanyl-D-alanine precursors and not with the penicillin-binding proteins that are the target of penicillin. Despite these theoretical advantages, the dearth of clinical data does not allow a recommendation for the use of vancomycin in STSS.

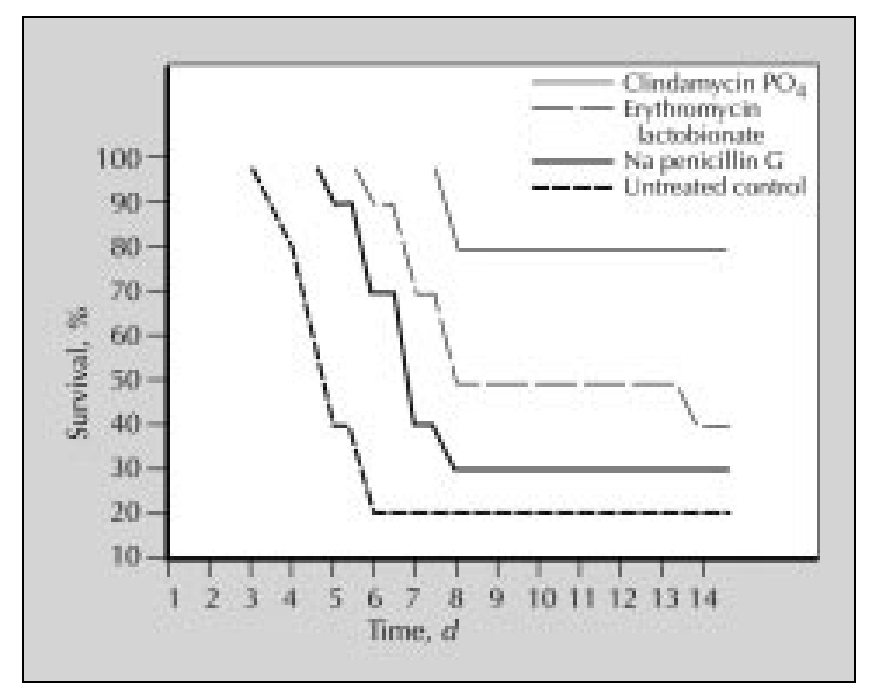

Figure 2. The survival of mice treated 6 hours after infection. G roups of 10 mice received $3.5 \times 10^{9}$ log-phase colony-forming units of Streptococcus pyogenes. Antibiotics were administered 6 hours after initiation of infection and were continued every 4 hours for a total of 4 doses. Animals were observed for 14 days, and the percent survival was calculated. Adapted from Stevens et al. [48]; with permission.

\section{Intravenous immunoglobulins}

If STSS is indeed a toxin-mediated disorder, then administration of antitoxic antibodies might be efficacious in its therapy. Specific antisera against streptococcal toxins are not available for human use, nor it is known which toxins are most intimately involved in the pathogenesis of thi disease. A possible source of such antitoxic antibodies $i$ intravenous human pooled polyspecific immunoglobulin G (IVIG). There have been a few case reports of dramatic improvement of STSS patients after administration of IVI $[19,39,53-56]$. In a comparative observational study, the 30-day survival of 21 STSS patients receiving IVIG was $34 \%$, while that of 32 patients not receiving this therapy was $67 \%(P=0.02)$ [57].

Multiple mechanisms have been postulated to explain a putati ve favorable effect of IVIG in the management of STSS [58]. IVIG neutralizes the superantigenic effect of the streptococcal toxins [59] and strongly inhibits the production of TNF and interleukins. It reduces blast transformation and inhibits lymphokine production (in particular TNF- $\beta$ and interferon- $\gamma$ ) by SPE-A-stimulated peripheral blood mononuclear cells in vitro, even when added 24 hours after stimulation [60]. It al so inhibits complementmediated damage by binding to $\mathrm{C} 3 \mathrm{~b}$ and $\mathrm{C} 4 \mathrm{~b}$ and might modulate the activity of the reticuloendothelial system by binding to, and functionally blocking, Fc receptors of macrophages and monocytes [58].

Intravenous immunoglobulin is obtained by poolin plasma of thousands (often 15,000) of blood donors and isolating the IgG fraction [58]. The half-life of infused IVIG is similar to that of IgG in normal human serum: 3 weeks in the case of IgG1, IgG2, and IgG4, and 1 week in the case of IgG3 [58]. Its composition resembles the lgG subclass distri- 
bution corresponding to that of normal serum. It contains antibodies to a number of toxic substances, including multiple streptococcal superantigens [61]. However, different commercial brands or even different lots of the same IVIG brand exhibit great variability in their neutralizing activity against purified and mixed group A streptococcal superantigens [62], making the standardization of this treatment and the recommendation of a dosage very difficult. Multiple doses may be necessary to neutralizeall the potential pyrogenic exotoxins, particularly SPE-A [40,62].

The dosage used in the different case reports ranges from 0.15 to $1.0 \mathrm{~g} / \mathrm{kg}$ body weight given for 1 to 5 consecutive days $[19,39,53-57,63]$. At this point, data in support of the use of IVIG are still largely theoretical. Considering the high mortality of full-blown STSS, and while awaiting more definitive data, use of this agent does seem reasonable in life-threatening cases.

\section{Corticosteroids}

Steroids may inhibit cytokine production, as well as inhibit the toxic al teration of vascular permeability [64]. Also, about one third of patients at stress have low cortisol values in relation to the stress situation [64]. There are fe reports on the use of corticosteroids in the management of STSS [55,64]. In most cases, these patients were also treated with antibiotics, IVIG, dialysis-plasma exchange, and other therapeutic modalities; they were all uncontrolled. It should be noted, however, that extensive controlled studies in septic shock caused by other bacterial agents have failed to show any benefit for the use these agents. For this reason, corticosteroids cannot be recommended in the treatment of STSS at the present time.

\section{Anti-tumor necrosis factor monoclonal antibodies}

There are scant data on the use of monoclonal antibodies (mAB) against TNF- $\alpha$ in the treatment of STSS. In a study of baboons with STSS induced by a strain producing pyrogenic exotoxin A, early treatment with anti-TNF mAB markedly improved arterial blood pressure and tissue perfusion and decreased mortality from $100 \%$ to 50\% [34]. Further studies are needed to darify the role of anti-TNF mAB in the management of STSS.

\section{Plasmapheresis}

In a series of 11 patients with STSS in Sweden [64], seven recei ved plasma exchange therapy. The primary rationale for plasma exchange is the removal of potential toxic substances (ie, anaphylotoxins, proteases, cell debris, cytokines, bacterial exo- and endotoxins) from the patient's plasma and replenishment of normal plasma constituents consumed in the inflammatory process [64]. It was found that plasmapheresis patients required less dialysis days (mean 7 days) than those who did not receive plasmapheresis (mean 20 days). These findings, although promising, still need to be confirmed in larger groups of patients.

\section{Immunization}

The increase in highly lethal GAS infections such as STSS, the persistence of acute rheumatic fever in the developing world, and the recent resurgence of acute rheumatic fever in the United States have led to renewed interest in the development of a GAS vaccine Research on such a vaccine has focused primarily on $M$ protein, because type-specific opsonic antibodies to this protein are the basis of acquired human immunity against GAS. Attempts to develop such a vaccine have been impeded by the fact that antibodies to $M$ proteins crossreact with a variety of human tissues, including heart and synovium [65]. The extent to which such antigenic mimicry plays a role in the pathogenesis of acute rheumatic fever remains unknown. Advances in our knowledge of the genetics, structure, and function of the M protein molecule are now making it possible to separate epitopes responsiblefor immunity from those shared with human tissues. It has also been learned that the distal (variable) portion of the $\mathrm{M}$ protein fibrils possesses the epitopes conferring type specificity, while the more proximal (conserved) portions are widely shared among different $M$ protein types. This information has spawned tw different approaches.

The first approach is recombinant, multival ent $\mathrm{M}$ protein vaccine. This approach involves constructing recombinant hybrid proteins that contain amino-terminal peptides of multiple different $M$ proteins linked in tandem. Although there are over 90 GAS M protein types, a vaccine composed of approximately a dozen would encompass the great majority of strains currently causing life-threatening invasive and nonsuppurative GAS disease in the United States. This approach is similar to that employed in the 23-valent pneumococcal vaccine So far, a gene that encodes an octavalent protein has been constructed and proven to elicit type-spe dific immunity to all eight $M$ types in rabbits [65]

The second approach is non-type-specific M protein. vaccines formulated from the conserved (so-called Crepeat) portion of the $M$ protein molecule have been linked to cholera toxin B subunit and vaccinia virus as vectors. When administered orally or intranasally, such vaccines have protected mice agai nst colonization and infection with several GAS serotypes. The commensal streptococcal organism, Streptococcus gordonii, has been genetically engineered to produce the C-repeat region o the $M$ protein, and when this genetically altered organism is administered orally, it induces a secretory IgA, serum IgG, and T-cell response to the recombinant antigen [65].

Other approaches are al so being explored. One of these focuses on C5a peptidase, an enzyme produced by GAS that inactivates complement factor $\mathrm{C} 5 \mathrm{a}$, a potent chemotaxin. Immunization with this enzyme induces high concentrations of salivary IgA and serum IgG in animals, thusinactivating the peptidase and facilitating clearance of the bacteri from tissue sites. If successful, this approach would obviate problems posed both by the multiplicity of GAS M protein types and of cross-reactivity between GAS and human tissues. 
Although the group A specific carbohydrate has traditionally been thought not to play a role in human immunity, recent observations have challenged this dogma. If these results are confirmed, they would provide anothe approach to GAS immunization [65].

\section{Prophylaxis of contacts}

Several studies have shown the potential for transmission of invasive GAS disease in nursing homes, and from patients to household contacts and heal th care workers $[36,66,67]$. In the Ontario study [17], the risk of subsequent invasive disease among household contacts has been estimated to be 2.9 per $1000(95 \% \mathrm{Cl}, 0.8-7.5)$, a figure almost 200 times the risk in the general population and similar to the risk of secondary meningococcal infection [68•]. This estimation is based on a series that encountered only four subsequent cases from 1360 contacts during a 4year surveillance [17], numbers that limit the degree to which these results can be generalized. Recently, an expert panel was convened to consider whether sufficient data were available to recommend antimicrobial prophylaxis to prevent subsequent invasive GAS infections among household contacts of index patients [68 $]$. The limited amount of data precluded a firm recommendation regarding routine prophylaxis. Special consideration might well be given to contacts of patients who have severe GAS disease (STSS or necrotizing fasciitis); those at the extremes of age ( $>65$ years or $<1$ year of age); and those with chronic cardiac and pulmonary disease, diabetes mellitus, HIV infection, or injection drug users and al cohol abusers, all of whom may be at increased risk for invasive disease.

Certain regimens have proved effective in eradicatin GAS colonization from the oropharyngeal mucosa. It is not known, however, whether these regimens will prevent severe, invasive GAS infections or those occurring through a cutaneous portal of entry [68 ${ }^{\bullet}$.

If chemoprophylaxis is to be given, either empirical I or to culture-positive intimate contacts, it should be recalled that penicillin is relatively ineffective in erradicating asymptomatic pharyngeal GAS carriage. Other agents may be employed, including clindamycin or ampicillin-clavulanate. Recommendations for specific regimens have been publ ished el sewhere [51]. In a recent preliminary report, a 5-day course of azithromycin was highly effective in eradicating GAS from the nasopharynx in school mates of a child with invasi ve GAS disease. There was, however, a marked increase in the proportion of nasopharyngea Streptococcus pneumoniae isolates resistant to erythromycin [69].

\section{Conclusions}

Streptococcal toxic shock syndrome is a condition associated with high morbidity and mortality. Early recognition and prompt initiation of therapy are of utmost importance The patients should be aggressively resuscitated and cardiovascular, pulmonary, and renal function supported in an intensive care unit as necessary. Surgical debridement is often necessary and is virtually al ways needed in the presence of necrotizing fasciitis. Antibiotic therapy should be initiated immediately. Intravenous dindamycin, with or without high-dose penicillin, is the regimen of choice. Even though there is no definitive evidence regarding it effectiveness, the use of IVIG should be considered in severe cases.

\section{References and Recommended Reading}

Recently published papers of particular interest have been highlighted as:

- Of importance

-. Of major importance

1. Bisno AL, Stevens DL: Streptococcal infections in skin and soft tissues. N Engl J M ed 1996, 334:240-245.

2. Stevens DL: The toxic shock syndromes Infect D is Clin N orth Am 1996, 10:727-746.

3. Stevens DL, Tanner MH, Winship J, et al.: Severe group A streptococcal infections associated with a toxic shock-like syndrome and scarlet fever toxin A. N Engl J M ed 1989, 321:1-7.

4. Meyer MA: Streptococcal toxic shock syndrome complicating pre-septal cellulitis. Am J O phthalmol 1997, 123:841-843.

5. Arvand M, Schneider T, Jahn HU, Hahn H: Streptococcal toxic shock syndrome associated with marked gamma delta $T$ cell expansion: case report. Clin Infect D is 1996, 22:362-365.

6. Ralph ED, Bourne RB: Toxic shock syndrome in association with group-A streptococcal infection of a knee joint after a total knee arthroplasty: a case report. J Bone Joint Surg Am 1998, 80:96-98.

7. Devin B, McCarthy A, Mehran R, Auger C: Necrotizing fasciitis of the retroperitoneum: an unusual presentation of group $A$ Streptococcus infection. Can J Surg 1998, 41:156-160.

8. - Eriksson BKG, Andersson J, Holm SE, Norgren M: Epidemiological and clinical aspects of invasive group A streptococcal infections and the streptococcal toxic shock syndrome. Clin Infect D is 1998, 27:1428-1436.

Population-based surveillance of STSS cases occurring in Sweden. This report discusses risk factors for acquiring invasive GAS disease and developing STSS.

9. Zurawski CA, Bardsley M, Beall B, et al.: Invasive group A streptococcal disease in Metropolitan Atlanta: a population-based assessment. Clin Infect Dis 1998, 27:150-157.

10. Wagner JG, Schlievert PM, Assimacopoulos AP, et al.: Acute group G Streptococcus myositis associated with streptococcal toxic shock syndrome: case report and review. Clin Infect Dis 1996, 23:1159-1161.

11. Keiser P, Campbell W: Toxic strep syndrome associated with group C Streptococcus. Arch Intern M ed 1992, 152:882-884.

12. Efstratiou A: Pyogenic streptococci of Lancefield groups $C$ and $\mathbf{G}$ as pathogens in man. Soc Appl Bacteriol Symp Series 1997, 26:72S-79S.

13. Schlievert PM, GockeJE, Deringer JR: Group B streptococcal toxic shock-like syndrome: report of a case and purification of an associated pyrogenic toxin. Clin Infect D is 1993, 17:2631.

14. Gardam MA, Low DE, Saginur R, Miller MA: Group B streptococcal necrotizing fasciitis and streptococcal toxic shock-like syndrome in adults. Arch Intern M ed 1998, 158:1704-1708.

15. Hirose $Y$, Yagi $K$, Honda $H$, et al.: Toxic shock-like syndrome caused by non-group A beta-hemolytic streptococci. Arch Intern M ed 1997, 157:1891-1894.

16. LeelarasameeA, Nilakul C, Tien-Grim S, et al.: Streptococcus suis toxic-shock syndrome and meningitis (abstract). J M ed Assoc Thai 1997, 80:63-68. 
17. Davies HD, McGeer A, Schwartz B, et al. , and the Ontario Group A Streptococcal Study Group: Invasive group A streptococcal infections in Ontario, Canada. N Engl J M ed 1996, 335:547-554.

18. Gonzales-Ruiz A, Ridgway GL, Cohen SL, et al.: Varicella gangrenosa with toxic shock-like syndrome due to group AStreptococcus infection in an adult: case report. C lin Infect D is 1995, 20:1058-1060.

19. Nadal D, Lauener RP, Braegger CP, et al.: T cell activation and cytokine release in streptococcal toxic shock syndrome. J Pediatr 1993, 122:727-729.

20. Yang YJ, Liu CC, Wang SM, et al.: Streptococcal toxic shock syndrome complicating varicella in children (abstract). J Formos M ed Assoc 1997, 96:749- 753.

21. Harada K, Suzuki T, Suzuki A, et al. : Toxic shock-like syndrome after acupuncturation [abstract]. Kansenshogaku Zasshi 1997, 71:1066-1070.

22. Stevens DL: Could nonsteroidal antiinflammatory drugs (NSAIDs) enhance the progression of bacterial infections to toxic shock syndrome? Clin Infect D is 1995, 21:977-980.

23. Kaul R, McGeer A, Low D, et al.: Population-based surveillance for group A streptococcal necrotizing fasciitis: clinical features, prognostic indicators, and microbiological analysis of seventy-seven cases. Am J M ed 1997, 103:18-24.

24. Norrby-Teglund A, Newton D, Kotb M, et al.: Superantigenic properties of the group A streptococcal exotoxin SpeF (MF). Infect Immun 1994, 62:5227-5233.

25. Stevens DL: Superantigens: their role in infectious diseases. Immun Invest 1997, 26:275-281.

26. Johnson HM, Torres BA, Soos JM: Superantigens: structure and relevance to human disease. Proc Soc Exp Biol M ed 1996, 212:99-109.

27. Michie C, Scott A, Cheesbrough J, et al.: Streptococcal toxic shock-like syndrome: evidence of superantigen activity and its effects on T lymphocyte subsets in vivo. Clin Exp Immunol 1994, 98:140-144.

28. Manders SM: Toxin-mediated streptococcal and staphylococcal disease. J Am Acad D ermatol 1998, 39:383-398.

29. Norrby-Teglund A, Pauksens K, Norgren M, Holm SE: Correlation between serum TNFa and IL6 levels and severity of group A streptococcal infections. Scand J Infect D is 1995, 27:125-130.

30. - Muller-Alouf H, Gerlach D, DesreumauxP, et al.: Streptococcal pyrogenic exotoxin A (SPE A) superantigen induced production of hematopoietic cytokines, IL-12 and IL-13 by human peripheral blood mononuclear cells. M icrobial Pathogen 1997, 23:265-272.

This article characterizes the superantigenic activity of SPE-A and its possible role in the pathogenesis of STSS.

31. Muller-Alouf H, Alouf JE, Gerlach D, et al.: Comparative study of cytokine release by human peripheral blood mononuclear cells stimulated with Streptococcus pyogenes superantigenic erythrogenic toxins, heat-killed streptococci, and lipopolysaccharide. Infect Immun 1994, 62:4915.

32. Lukomski S, Sreevatsan S, Amberg C, et al.: Inactivation of Streptococcus pyogenes extracellular cysteine protease significantly decreases mouse lethality of serotype M3 and M49 strains. J Clin Invest 1997, 99:2574-2580.

33. Kapur V, Majesky MW, Li L, et al.: Cleavage of interleukin $\mathbf{1 b}$ (IL-1b) precursor to produce active IL-1b by a conserved extracellular cysteine protease from Streptococcus pyogenes. Proc N atl Acad Sci U S A 1993, 90:676-680.

34. Stevens DL, Bryant AE, Hackett SP, et al.: Group A streptococcal bacteremia: the role of tumor necrosis factor in shock and organ failure. J Infect D is 1996, 173:619-626.

35. Herwald H, Collin M, Muller-Esterl W, Bjorck L: Streptococcal cysteine proteinase releases kinins: a novel virulence mechanism. J Exp M ed 1996, 184:665-673.

36. Ichiyama S, Nakashima K, Shimokata K, et al.: Transmission of Streptococcus pyogenes causing toxic shock-like syndrome among family members and confirmation by DNA macrorestriction analysis. J Infect D is 1997, 175:723-726.
37. - Cockerill FR, MacDonald KL, Thompson RL, et al.: An outbreak of invasive group A streptococcal disease associated with high carriage rates of the invasive clone among school-aged children. JAM A 1997, 277:38-43.

This epidemiologic study demonstrated a high preval ence of asymptomatic carriage of an invasive GAS clone, thus raising the issue of the advisability of prophylaxis of contacts.

38. Norrby-Teglund A, Pauksens K, Holm SE, Norgren M: Relations between low capacity of human sera to inhibit streptococcal mitogens and serious manifestations of disease. J Infect $D$ is 1994, 170:585-591.

39. Mahieu LM, Holm SE, Goosens HJ, Van Acker KJ: Congenital streptococcal toxic shock syndrome with absence of antibodies against streptococcal pyrogenic exotoxins. J Pediatr 1995, 127:987-989.

40. Stevens DL: Editorial response: rationale for the use of intravenous gamma globulin in the treatment of streptococcal toxic shock syndrome. Clin Infect D is 1998, 26:639-641.

41. The Working Group on Severe Streptococcal Infections: D efining the group A streptococcal toxic shock syndrome: rationale and consensus definition. JAM A 1993, 269:390-391.

42. Centers for Disease Control and Prevention: Case definitions for infectious conditions under public health surveillance. Streptococcal toxic shock syndrome. M M W R 1997, 46:33-34.

43. Wood TF, Potter MA, Jonasson O: Streptococcal toxic shocklike syndrome: the importance of surgical intervention. Ann Surg 1993, 217:109-114.

44. Berger-Jekic O, Vuckovic-O pavski N, Ranin L: Susceptibility of beta-hemolytic streptococci to penicillin. Adv Exp M ed Biol 1997, 418:467-469.

45. Coonan KM, Kaplan EL: In vitro susceptibility of recent North American group A streptococcal isolates to eleven oral antibiotics. Pediatr Infect DisJ 1994, 13:630-635.

46. Holm SE: Invasive group A streptococcal infections (letter, comment). N Engl J M ed 1996, 335:590-591.

47. Stevens DL, Yan S, Bryant AE: Penicillin-binding protein expression at different growth stages determines penicillin efficacy in vitro and in vivo:an explanation of the inoculum effect. J Infect D is 1993, 167:1401-1405.

48. Stevens DL, Gibbons AE, Bergstrom R, Winn V: The Eagle effect revisited: efficacy of clindamycin, erythromycin, and penicillin in the treatment of streptococcal myositis. J Infect D is 1988, 158:23-28.

49. Bisno AL, Stevens DL: Streptococcal infections. In Principles and Practice of Infectious D iseases, edn 5. Edited by Mandell GL, Bennett JE, Dolin R. Philadel phia: WB Saunders; 1999, in press.

50. - Stevens DL, Madaras-Kelly KJ, Richards DM: In vitro antimicrobial effects of various combinations of penicillin and clindamycin against four strains of Streptococcus pyogenes. Antimicrob Agents Chemother 1998, 42:1266-1268.

Recent study evaluating thein vitro interaction between penidillin and clindamycin at clinical concentrations using time-kill studies for GAS.

51. Bisno AL, Gerber MA, Gwaltney JM, et al.: Diagnosis and management of group A streptococcal pharyngitis: a practice guideline. Clin Infect D is 1997, 25:574-583.

52. Holdsworth RJ, Smith D, Parratt D, Gunn A: Treatment of invasive Streptococcus pyogenes infection with vancomycin. J R Coll Surg Edinb 1994, 39:185-188.

53. Barry W, Hudgins L, Donta ST, Pesanti EL: Intravenous immunoglobulin therapy for toxic shock syndrome. JAM A 1992, 267:3315-3316.

54. Lamothe F, D'Amico $P$, Ghosn $P$, et al.: Clinical usefulness of intravenous human immunoglobulins in invasive group $A$ streptococcal infections: case report and review. Clin Infect D is 1995, 21:1469-1470.

55. Chiu CH, Ou JT, Chang KSS, Lin TY: Successful treatment of severe streptococcal toxic shock syndrome with a combination of intravenous immunoglobulin, dexamethasone and antibiotics. Infection 1997, 25:47-48.

56. Perez CM, Kubak BM, Cryer HG, et al. : Adjunctive treatment of streptococcal toxic shock syndrome using intravenous immunoglobulin: case report and review. AmJ M ed 1997, 102:111-1113. 
57. Kaul R, McGeer A, Norrby-Teglund A, et al.: Intravenous immunoglobulin therapy for streptococcal toxic shock syndromea comparative observational study. Clin Infect D is 1999, 28:800-807.

58. Mouthon L, Kaveri SV, Spalter SH, et al.: Mechanisms of action of intravenous immune globulin in immune-mediated diseases. Clin Exp Immunol 1996, 104:3-9.

59. Norrby-Teglund A, Kaul R, Low DE, et al.: Plasma from patients with severe invasive group A streptococcal infections treated with normal polyspecific IgG inhibits streptococcal superantigen-induced T cell proliferation and cytokine production. J Immunol 1996, 156:3057-3064.

60. Andersson J, Skansen-Saphir U, Sparrelid E, Andersson U: Intravenous immune globulin affects cytokine production in T lymphocytes and monocytes/macrophages. Clin Exp Immunol 1996, 104:10-20.

61. Norrby-Teglund A, Kaul R, Low DE, et al. : Evidence for the presence of streptococcal-superantigen-neutralizing antibodies in normal polyspecific immunoglobulin G. Infect Immun 1996, 64:5395-5398.

62. Norrby-Teglund A, Basma $\mathrm{H}$, Andersson J, et al.: Varying titers of neutralizing antibodies to streptococcal superantigens in different preparations of normal polyspecific immunoglobulin G: implications for therapeutic efficacy. Clin Infect D is 1998, 26:631-638.

63. Werdan K, Pilz G: Supplemental immune globulins in sepsis: a critical appraisal. Clin Exp Immunol 1996, 104:83-90.
64. Stegmayr B, Bjorck S, Holm S, et al.: Septic shock induced by group A streptococcal infection: clinical and therapeutic aspects. Scand J Infect Dis 1992, 24:589-597.

65. DaleJB, Cleary PP, Fischetti VA, et al.: Group A and group B streptococcal vaccine development: a roundtable presentation. Adv Exp M ed Biol 1997, 418:863-868.

66. DiPersio JR, File TM, Stevens DL, et al.: Spread of serious disease-producing M3 clones of group A Streptococcus among family members and health care workers. Clin Infect $D$ is 1996, 22:490-495.

67. Gamba MA, Martinelli M, Schaad HJ, et al.: Familial transmission of a serious disease-producing group $A$ Streptococcus clone: case reports and review. Clin Infect D is 1997, 24:1118-1121.

68. The Working Group on Prevention of Invasi ve Group A Streptococcal Infections: Prevention of invasive group A streptococcal disease among household contacts of case-patients. Is prophylaxis warranted? JAM A 1998, 279(15):1206-1210.

This is an expert consensus statement regarding the use of prophylactic antimicrobials for household contacts of patients with invasive GAS disease The availablestudies are well reviewed and analyzed, although lack of conclusive data precluded a dear recommendation.

69. Morita J, Kahn E, Thompson T, et al.: Eradication of oropharyngeal group A Streptococcus (GAS) with azithromycin. In Abstracts of the 36th Annual M eeting of the Infectious D iseases Society of America. Denver, 1998:570 Sa. 